\title{
Variation in the Qualities of Instruction Methods Adopted by Different Kindergartens in Hong Kong
}

\author{
Wai Ling Chan, The Hong Kong Institute of Education, China \\ Nirmala Rao, The University of Hong Kong, China
}

\begin{abstract}
This study examined the learning and teaching approaches used in three kindergartens in Hong Kong. The kindergartens used the same curriculum package and were assessed as being of "good", "acceptable" and "unsatisfactory" quality, respectively, by the regulatory body. The participants were five kindergarten teachers and their students, and five specialists in pre-primary education who provided an independent assessment of kindergarten quality. Each teacher was observed for three hours a day over three consecutive days. The specialists discussed videotaped observations of learning activities from each of the kindergartens in a focus group, and rated kindergarten quality. The results indicated that the ratings of the regulatory body and the specialists were consistent and appeared to be informed by the criteria for "developmentally appropriate practices". The low-quality classroom was teacher-directed, engaged mainly in chalk-and talk and paper-and-pencil activities, and involved few interactions between the teacher and the children or among the children. The children in the other two kindergartens engaged in authentic learning activities, learned in small groups, appeared cognitively engaged and had many interactions with the teacher and other children. Although the kindergartens claimed to use the Montessori, Project and Unit approaches, the specialists felt that none of them actually implemented their purported approaches with fidelity. On the basis of these findings, suggestions are made to improve the quality of learning and teaching in pre-primary schools.
\end{abstract}

Keywords: Learning and Teaching, Quality, Kindergarten, Hong Kong

\section{Introduction}

A Il of Hong Kong's pre-primary institutions belong to the private sector and are either non-profit-making or private independent schools. Both types are run by voluntary organisations or private individuals/organisations. Unlike primary and secondary schools, they do not receive full subsidies from the government, although they are expected to implement the educational reforms that apply to the former. Kindergartens must register with the Education Bureau (EDB) and submit to regular inspections.

The quality of pre-primary education in Hong Kong is monitored primarily by the EDB, which since 2000/01 has conducted annual Kindergarten Quality Assurance Inspections to assess the extent to which preschools are working toward high-quality learning and teaching (Hong Kong Government 2000). Inspectors use a variety of methods to assess lesson quality, including observing activities, examining resources, reviewing documentary evidence and engaging in discussions with teachers and parents. The inspection reports become public documents and are available online. If a government-subsidised preschool fails an inspection, then its subsidies may be withdrawn (Hong Kong Government 2000).

Since 2007, the HKSAR government has provided tuition fee subsidies for all children aged three to six using a "voucher" scheme. From the 2012/13 academic year, only non-profit-making kindergartens that meet government quality standards are eligible to redeem these vouchers. The stated aim of all of these government policies and measures is to raise the quality of pre-primary education in Hong Kong.

In line with the quality review system under the voucher scheme, many pre-primary educators feel great pressure to implement good learning and teaching approaches. Most of the pre-primary institutions have adopted new teaching approaches to improve their competitiveness

The International Journal of Early Childhood Learning

Volume 19, 2013, thelearner.com, ISSN: 2327-7939

(C) Common Ground, Wai Ling Chan and Nirmala Rao, All Rights Reserved

Permissions: cg-support@commongroundpublishing.com 


\section{THE INTERNATIONAL JOURNAL OF EARLY CHILDHOOD LEARNING}

and teaching quality. Wong, Yung and Chan (2007) found that most pre-primary institutions in Hong Kong claim to adopt the constructivist perspective, which is considered a hallmark of highquality pre-primary education.

The focus of this paper is the learning and teaching conditions in three kindergartens, assessed by the Hong Kong Education Bureau (EDB) as having different levels of quality "good", "acceptable" and "unsatisfactory" - in the same year. These three non-profit kindergartens adopt different teaching approaches to raise their learning and teaching quality. They all use the same curriculum package, and are thus considered to reflect the overall learning and teaching situation in Hong Kong pre-primary institutions.

The two main objectives of the study were to identify the learning and teaching approaches used in kindergartens of varying quality and to compare the EDB ratings of kindergarten quality with the ratings of specialists (pre-primary teacher educators). The expectation was that the higher-quality kindergartens would feature child-centred pedagogy and teachers concerned with promoting children's engagement in learning. As there has been extensive public consultation on the kindergarten quality indicators and the government is responsive to feedback from academics, a fair degree of consistency between the EDB and specialists' ratings was also anticipated. The two research questions were as follows. i) How do the learning and teaching approaches adopted in the three kindergartens varying in terms of quality? ii) What are the learning and teaching methods used in the three kindergartens with relation to quality preprimary education?

Most global indicators of pre-primary quality have been found to be significantly related to the cognitive and social development of children (Burchinal et al., 2000), and show that there is a close relationship between high-quality pre-primary education and child outcomes. In Hong Kong, the EDB has actively promoted quality assurance to improve the quality of pre-primary education, and various other countries also use quality assurance assessments. What actually constitutes quality pre-primary education must, however, be defined before such assessments can be of value. The definitions of quality from other studies are thus examined here before the quality of local learning and teaching is investigated.

\section{Preschool Quality}

A study of kindergarten classrooms conducted by Pianta et al. (2002) showed that quality was related to classroom-level variables, such as the general character of the classrooms, teacherchild interaction and teaching processes. Although a universal definition of high-quality early education is elusive and subject to societal and cultural values and beliefs (Moss, Dahlberg and Pence 2000), it is generally construed as education that nurtures children (Galinsky et al. 1994). High-quality pedagogical practice is generally considered to comprise active interaction, good teacher-student communication and active student participation (National Association for the Education of Young Children [NAEYC] 2006; Sheridan 2001; Sylva et al. 2004). Children in these programmes always learn, and their teachers are dedicated to stimulating their students' physical, socio-emotional and intellectual development. According to NAEYC professional standards for developmentally appropriate practice (DAP), caregivers in high-quality environments are responsive to children's questions and requests and have frequent, positive interactions with children to encourage their independence and engagement (Bredekamp 1987). Stipek (1993) reported the emotional climate in child-centred classrooms to be more positive than that in their didactic counterparts, although there is less of an academic focus.

\section{The Importance of High Quality Preschool Education}

Many recent studies have examined the relationship between pre-primary educational quality and children's later learning experiences. Longitudinal studies have revealed that such education has 
a positive effect on academic performance, self-esteem and attitudes toward lifelong learning (Burchinal et al. 2000; NICHD 2002; Sylva 1994; U.S. Department of Education 2000). There is also substantial evidence of the effects of educational quality on children's cognitive, social and emotional outcomes (Andersson 1989; Belsky et al. 2007; Ceglowski and Bacigalupa and 2002; Clifford and Bryant 2003; Siraj-Blatchford et al. 2002; Sylva et al. 2004). Recent global attention and significant government investment has highlighted the importance of pre-primary education because of the benefits it can bring. A significant part of this attention relates to quality (OECD 2012).

It is important to determine which aspects of preschool quality contribute to positive outcomes for children. Pianta et al. (2002) considered quality to be related to such classroomlevel variables as classroom climate, teacher-child interaction and teaching processes. The teacher-child relationship is also seen as important to children's development (Kamii and Ewing 1996). Research has shown that children exposed to higher levels of teacher-child verbal interaction perform better in language tests than those exposed to high levels of peer interaction alone (McCartney 1984). A good relationship with teachers also allows children to feel accepted and safe, and to integrate into and cooperate with classroom activities (Pianta et al. 2002).

Although no empirical studies on the relationship between preschool quality and child outcomes have been carried out in Hong Kong, a study by Clarke-Stewart and Allhusen (2002) revealed the importance of learning and teaching to pre-primary educational quality. This finding provided the impetus for this study, which examined learning and teaching quality in three Hong Kong kindergartens.

\section{Approaches that the Three Kindergartens Claim to Use in their Curricula}

There is no standardised curriculum for pre-primary education programmes in Hong Kong, but the EDB issues curriculum guidelines. Thus, kindergartens have considerable flexibility and room for elaboration in organising teaching content and in the way this content is taught.

Little research has been conducted on the implementation of pre-primary teaching approaches in Hong Kong, although the Unit Approach, Project Approach, Thematic Approach and Montessori Approach are typically used in pre-primary education. The small number of local studies on the quality of learning and teaching highlights the importance of this study.

\section{The Project Approach}

The Project Approach, which was developed by Katz and Chard (2000), involves the in-depth study of a topic or concept that has personal meaning to children. The children themselves often suggest the project topics and actively participate in planning the activities, which may carry on for several days or weeks. Project work is neither direct instruction nor spontaneous play, but emerges from children's interests in real-life concepts or experiences. Both the planning and implementation of the projects encourage children's thinking, problem-solving and socialnegotiation skills (Katz \& Chard 2000). Investigation is emphasised in the Project Approach, and children are encouraged to act as data collectors. A wide variety of concepts and skills in different subject-matter areas can be covered in a project, such as writing, reading, building, calculating, problem solving, analysing and observing (Katz \& Chard 2000). Children choose the focus, activities and the amount of time spent on each topic. Projects proposed by Katz and Chard may involve baskets, shadows and light, shoes, homes, chairs, water and school buses. In a project on school buses, for example, children go outside of the classroom to study specific aspects of school buses, such as the types of wheels and tyres. They also engage in activities inside the classroom, such as constructing a school bus out of clay or cardboard. Through this approach, children link what they have learned outside of the classroom to the tasks and activities in which they are engaged inside the classroom. 


\section{THE INTERNATIONAL JOURNAL OF EARLY CHILDHOOD LEARNING}

\section{The Montessori Approach}

The Montessori Approach refers to educational activities that conform to the pedagogical thinking of Maria Montessori (1964). This approach is mainly used in Montessori schools or teaching institutions authorised and approved by the Association Montessori Internationale (AMI) or the American Montessori Society (AMS), and brought into practice by teachers trained and approved by the AMI or AMS. Characteristics of the Montessori Approach include mixed age groups, a set of specifically designed educational materials, children being given sufficient time and space to select and autonomously manipulate the teaching tools, cooperation, and no tests. Teachers provide assistance to children in the form of individual or group guidance to develop their academic and social skills.

According to Montessori (1964), although there are many conditions for successful education, the most important are that there should be a suitable teaching and learning environment that includes all of the necessary information and practice tools, and that sufficient preparatory work is carried out by teachers, which means that teachers should have a real understanding of the activities involved.

Huo and Qi (2008) pointed out that the Montessori teaching tools are mostly mechanical. After more than 40 years of use in pre-primary education all over the world, they are proven to be effective teaching tools for the physical training of children, and are recognised in academic circles as indispensable teaching tools for pre-primary education. The Montessori Approach requires that teachers only demonstrate the correct use of the teaching tools and teach children the rules of their use; the design and transformation of the tools are left to the children to understand and explore. Furthermore, there is no fixed form or template for the tools, which allows children to use their own imagination and thinking skills.

The most distinctive point of Montessori education lies in the role played by Montessori teachers, which differs from that of teachers in traditional schools. Teachers in Montessori schools allow children to get in touch with the teaching materials on their own, and act as a bridge between children and the teaching environment. In this way, teachers are monitors and administrators of the "environment”.

\section{The Unit Approach}

"Unit" had become a popular word in the field of education by the early $20^{\text {th }}$ century, although the meaning of the word in terms of the Unit Approach is somewhat obscure. According to Morrison (1931), certain "child-centred" or "society-centred" modern educators think that traditional subject-divided teaching lacks integration, thus causing children to learn only fragmented knowledge that is not easy to apply and resulting in material that lacks interest and meaning. The answer to this problem is to generate teaching materials in meaningful combinations or units, which gives rise to more meaningful learning.

Sun (1969) suggested that a unit is a life-centred, purposeful, cross-subject and complete learning activity, which needs a longer learning time and provides students with the opportunity to develop social behaviour. Wang (1987) posited that the Unit Approach refers to a complete teaching activity that has a clear teaching aim, adopts teaching materials that fit in closely with this aim, uses efficient methods to instruct children to learn and has a concrete standard for inspecting the teaching outcome. Students acquire a complete learning experience, rather than fragmented knowledge or simply abstract words and symbols from books.

The Unit Approach thus involves complete teaching activities. It values the development of a well-rounded personality and abandons totally teacher-centred situations. Its aims are to enhance children's knowledge and skills and cultivate their ideas and attitudes so that they can change their behaviour and strengthen their ability to adapt to their living environment.

When teachers use the Unit Approach, the design of the activities should allow children room for development and interaction. The design of the activities should also make children the 
subject and should provide opportunities for exploration, personal experience and manipulation. More consideration should also be given to group activity planning. In the practice of teaching, teachers should make good use of higher-order questions to arouse the children's interest and increase their depth of learning, and should also cater to their individual differences (Chien 2002).

According to the programme handbook of the Hong Kong Christian Service (1994), the Unit Approach suggests that all activities be designed around a concept. Every unit concept is introduced by different activities, such as creating pictures and stories, and every activity centres on the unit concept. This approach enables children to understand each concept from different angles and acquire complete knowledge of it, and to avoid acquiring fragmented, dispersed knowledge and techniques. The ideas on which the activities are based mostly come from the children's surrounding environment and can be applied in daily life, rather than being disconnected from reality. As the curriculum content is related to real life, very often on-site visits or school visits by social celebrities and parents are arranged.

The similarities and differences between the three teaching approaches outlined in this section are summarised succinctly by Liu (2003):

The Unit Approach, Project Approach and Thematic Approach all use a theme to run through and unite the thematic curriculum of children's learning content. The differences among the Unit Approach, Project Approach and Thematic Approach lie in teachers' and children's power to make decisions of the program, and to what extent teachers have planned for program implementation (p. 122).

Although these different teaching approaches have different pros and cons, the decision as to how to teach effectively should lie not in whether to use the Project Approach or the Unit Approach, but in how to allow children to participate in planning the learning process and how to adjust the planning of the teaching activities according to children's interests.

\section{Method}

\section{Participants}

The main participants were five pre-primary education specialists (Specialists A-E) who were teacher educators in a local tertiary institution. They observed five kindergarten teachers from the three participating kindergartens and their $79 \mathrm{~K} 2$ students (4- and 5-year-olds). In addition to general knowledge about the pre-primary curricula, the specialists had expertise in one or more of the following areas: pre-primary mathematics, physical development, socio-moral development and art. The kindergartens were purposively selected to ensure that the sample comprised institutions that the EDB had assessed in the same year to be of different quality levels. Those selected also adopted the same curriculum package (including textbooks), thus ensuring that any variation in learning and teaching reflected the methods of instruction, rather than the curriculum content. The three kindergartens were government-aided, not-for-profit institutions located in different regions of Hong Kong, had been in operation for a similar number of years, and had been rated "good" (Kindergarten A), “acceptable” (B) and "unsatisfactory" (C) by the EDB. Kindergarten C had received a warning letter advising it to make improvements to ensure that it continued to receive subsidies.

The most widely consulted quality measure for learning and teaching by pre-primary institutions in Hong Kong is the "Guide to Using the Pre-primary Performance Indicators in Learning and Teaching” by Wong et al. (2003). This guide was developed based on the second edition of "Learning and Teaching from the Pre-primary Performance Indicators", which was the result of collaboration between the EDB and the Social Welfare Department (SWD). The "Class 


\section{THE INTERNATIONAL JOURNAL OF EARLY CHILDHOOD LEARNING}

Observation Form” (shown in Appendix 1) used in the current study was designed with reference to this guide.

\section{Procedure}

The five specialists formed a focus group, and viewed three hours of videotaped observations selected to present a range of learning and teaching activities in the three kindergartens. Teachers' actual classroom practices are of vital importance to children's learning, and are also the main means by which pre-primary teaching and learning in Hong Kong is evaluated. The specialists were first asked to rate the kindergartens' learning and teaching quality in four areas activity design, activity implementation, classroom culture and teacher's performance - on a questionnaire using a Likert-type scale ranging from 1 (not at all) to 5 (to a great extent). A rating value of 6 (don't know or not applicable [NA]) was also allowed when there was insufficient evidence for them to make a judgement on a given indicator. The questionnaire also included ratings of the likely effect of instruction and a capsule rating of lesson quality.

The specialists' overall assessment of learning and teaching approaches in the three kindergartens were then elicited by four questions, designed to initiate open-ended discussion in the focus group. This focus group discussion served as the primary method of collecting descriptive data. The discussion ranged from teaching modes, methods and strategies, to classroom quality and correspondence with the ideals of pre-primary educational quality. After the group discussion, the specialists were interviewed separately to gain a better understanding of their assessments (see Appendix 2) and how they compared with those of the EDB and of the researcher.

\section{Results}

The discussions and interview transcripts were analysed in two rounds to determine the specialists' opinions of the teaching conditions and teachers' attitudes and beliefs. Validation of the data was achieved by triangulating the specialist and participant-observer (researcher) perspectives on the classroom events. Theoretical validation was achieved by discussing the emerging conclusions in the focus group. Moreover, the researcher has more than 30 years of experience in pre-primary education, which renders her a study instrument in her own right, further boosting the reliability and validity of the analysis and observations.

\section{Focus Group Ratings}

Kindergartens A and B consistently outranked C in all four criteria on the questionnaire - activity design, activity implementation, classroom culture and teacher's performance - as seen in Table 1 and in the following discussion. Differing slightly from the results of the EDB quality assessments of these schools, however, Kindergarten B generally achieved higher scores than A.

Kindergartens A and B were rated satisfactory in terms of activity design, with the latter achieving a slightly higher rating (3.72) than the former (3.27). In contrast, the mean rating for Kindergarten $\mathrm{C}$ was only 1.93. Kindergarten $\mathrm{B}$ also received the highest score for activity implementation (3.87), although Kindergarten A was not far behind (3.47). Kindergarten C's score for this criterion was considerably lower at 1.53. Kindergarten B also outranked the other two in terms of classroom culture, achieving a mean score of 4.20 , compared with 3.68 for Kindergarten A and a very poor 1.23 for Kindergarten C. Finally, in terms of teachers' performance, Kindergarten A achieved a mean score of 3.55, Kindergarten B 3.92 and Kindergarten C 1.62 (see Table 1). 
CHAN AND RAO: VARIATION IN QUALITIES OF INSTRUCTION METHODS IN KINDERGARTENS

Table 1: Specialists' ratings of the three kindergartens

\begin{tabular}{|c|c|c|c|c|}
\hline & & KG A & KG B & KG C \\
\hline \multirow[t]{8}{*}{ Design of Activities } & $\begin{array}{l}\text { 1. The design of the activities reflected careful planning } \\
\text { and organisation. }\end{array}$ & 3.20 & 3.80 & 2.40 \\
\hline & $\begin{array}{l}\text { 2. The teaching methods matched the children's } \\
\text { developmental progress. }\end{array}$ & 3.60 & 3.80 & 2.20 \\
\hline & $\begin{array}{l}\text { 3. The teaching programme included all development } \\
\text { domains. }\end{array}$ & 3.70 & 4.25 & 2.70 \\
\hline & $\begin{array}{l}\text { 4. The teaching plan included provision for individual } \\
\text { differences. }\end{array}$ & 3.00 & 3.60 & 1.80 \\
\hline & $\begin{array}{l}\text { 5. The variety of learning experiences allowed children to } \\
\text { have a choice. }\end{array}$ & 3.00 & 3.80 & 1.60 \\
\hline & $\begin{array}{l}\text { 6. The learning experiences involved problem-solving } \\
\text { activities. }\end{array}$ & 3.20 & 3.40 & 1.40 \\
\hline & 7. Creative learning experiences were planned. & 3.20 & 3.40 & 1.40 \\
\hline & Mean Score & 3.27 & 3.72 & 1.93 \\
\hline \multirow[t]{10}{*}{$\begin{array}{l}\text { Implementation of } \\
\text { Activities }\end{array}$} & $\begin{array}{l}\text { 8. Age-appropriate learning experiences were provided } \\
\text { that matched learning objectives. }\end{array}$ & 3.40 & 4.00 & 2.00 \\
\hline & $\begin{array}{l}\text { 9. Experiences that fostered children's learning were } \\
\text { provided. }\end{array}$ & 3.20 & 4.20 & 1.40 \\
\hline & $\begin{array}{l}\text { 10. The activities were systematically adjusted to } \\
\text { accommodate children's needs and interests. }\end{array}$ & 3.00 & 3.80 & 1.20 \\
\hline & $\begin{array}{l}\text { 11. A safe environment with adequate facilities to facilitate } \\
\text { learning was provided. }\end{array}$ & 4.25 & 4.00 & 2.00 \\
\hline & $\begin{array}{l}\text { 12. The environment stimulated learning and facilitated } \\
\text { problem-solving and exploration. }\end{array}$ & 3.40 & 3.60 & 1.60 \\
\hline & $\begin{array}{l}\text { 13. The activities supported children's choices and } \\
\text { collaborative learning. }\end{array}$ & 3.40 & 3.60 & 1.40 \\
\hline & $\begin{array}{l}\text { 14. The activities built upon children's abilities and } \\
\text { interests. }\end{array}$ & 3.40 & 3.80 & 1.40 \\
\hline & 15. The activities were adapted to individual differences. & 3.20 & 3.40 & 1.00 \\
\hline & $\begin{array}{l}\text { 16. The activities promoted children's self-care skills, self- } \\
\text { confidence and sense of security. }\end{array}$ & 4.00 & 4.40 & 1.80 \\
\hline & Mean Score & 3.47 & 3.87 & 1.53 \\
\hline \multirow[t]{3}{*}{ Classroom Culture } & 17. The active participation of all was encouraged. & 3.60 & 4.40 & 1.80 \\
\hline & $\begin{array}{l}\text { 18. There was a climate of respect for children's ideas, } \\
\text { questions and contributions. }\end{array}$ & 3.80 & 4.40 & 1.00 \\
\hline & $\begin{array}{l}\text { 19. Interactions reflected collaborative working } \\
\text { relationships between teachers and children. }\end{array}$ & 4.00 & 4.00 & 1.20 \\
\hline
\end{tabular}




\section{THE INTERNATIONAL JOURNAL OF EARLY CHILDHOOD LEARNING}

\begin{tabular}{|c|c|c|c|c|}
\hline & $\begin{array}{l}\text { 20. Questions were raised to enhance and extend } \\
\text { children’s learning (e.g., provocative and open- } \\
\text { ended questions). }\end{array}$ & 3.20 & 3.60 & 1.40 \\
\hline & $\begin{array}{l}\text { 21. Communication with children improved mutual } \\
\text { respect and relationships. }\end{array}$ & 3.75 & 4.80 & 1.00 \\
\hline & $\begin{array}{l}\text { 22. Different strategies were used to communicate with } \\
\text { individual children. }\end{array}$ & 3.75 & 4.00 & 1.00 \\
\hline & Mean Score & 3.68 & 4.20 & 1.23 \\
\hline Teachers’ Performance & $\begin{array}{l}\text { 23. The teacher made eye contact with the children during } \\
\text { lessons. }\end{array}$ & 3.50 & 4.40 & 2.00 \\
\hline & 24. The teacher allowed the children to have thinking time. & 3.50 & 3.40 & 1.20 \\
\hline & 25. The teacher asked a large number of questions. & 3.50 & 3.60 & 2.00 \\
\hline & $\begin{array}{l}\text { 26. The teacher attributed children's successes to their } \\
\text { efforts. }\end{array}$ & 3.75 & 4.40 & 1.40 \\
\hline & $\begin{array}{l}\text { 27. The teacher conveyed a sense of enthusiasm in the } \\
\text { presentation of tasks. }\end{array}$ & 3.50 & 4.60 & 1.60 \\
\hline & 28. The teacher asked the children to restate answers. & 3.00 & 3.20 & 1.20 \\
\hline & $\begin{array}{l}\text { 29. The teacher gave clear and detailed instructions and } \\
\text { explanations. }\end{array}$ & 3.50 & 4.20 & 2.40 \\
\hline & 30. The teacher gave a moderate amount of praise. & 3.80 & 4.40 & 1.20 \\
\hline & $\begin{array}{l}\text { 31. The teacher made brief contact with individual } \\
\text { children. }\end{array}$ & 4.00 & 3.80 & 2.00 \\
\hline & $\begin{array}{l}\text { 32. The teacher encouraged the children to ask questions } \\
\text { and initiate verbal interactions. }\end{array}$ & 3.50 & 3.20 & 1.20 \\
\hline & Mean Score & 3.55 & 3.92 & 1.62 \\
\hline
\end{tabular}

\section{Focus Group Discussion}

The focus group discussions shed light on the teaching approaches, strategies and materials in the three kindergartens. Kindergarten A implemented the Montessori Approach, which emphasises the use of mixed-age activities, and Kindergarten B the Project Approach, which emphasises children's active exploration and discovery. Kindergarten $\mathrm{C}$, in contrast, implemented the Unit Approach and generally adopted a didactic teaching approach in which the teacher talks and the children listen, and teacher-child interaction took the form of demonstration and repetition. The teaching in Kindergartens A and B was interactive and the teachers made use of a variety of materials, encouraged questions, offered opportunities for hands-on experience and regularly praised and encouraged the children. The teaching materials in Kindergarten C, in contrast, were chiefly worksheets and textbooks, and there was little teacher-child interaction. The teaching strategies mainly consisted of repetition and explanation, and the children were frequently criticised and rarely given positive responses.

\section{General View of Classroom Activities}


The specialists concurred that Kindergarten A had a rich classroom environment, with enthusiastic teachers who were willing to interact with the children and participate in activities, emphasised moral education and paid attention to children's self-learning abilities. However, they questioned the extent to which teaching theories were being put into practice, and Specialist B described the teaching tools as "relatively monotonous". In Kindergarten B, which claimed to use the Project Approach, the only project work observed was an "interview" carried out with the school's principal. Specialists A and C agreed that the teacher understood the theory underpinning this activity, but the former felt that she failed to use an appropriate learning strategy, and the latter that she failed to convey its purpose to the children. The specialists largely agreed that the classroom culture in Kindergarten B was good, and the teacher was positive and responsive to the children. The situation in Kindergarten $\mathrm{C}$ was very different. The five specialists agreed that the teaching approach was traditional, with the teacher paying a great deal of attention to results but failing to address the developmental needs and learning abilities of individual children. They also noted that she failed to provide effective and authentic teaching materials, and instead emphasised memorisation. She also ignored the children's responses and frequently used a punitive tone, resulting in a distant teacher-child relationship.

\section{General View of Teachers' Attitudes}

Specialist B praised the teaching attitudes of both Kindergarten A teachers, particularly their concern for the children. An expert in child development, this specialist was particularly interested in whether the teachers sought to enhance the children's sense of responsibility. Specialist D was very impressed with one of the Kindergarten B teachers, praising her teaching attitude, constant smile and regular praise and encouragement of the children during group activities. Again, the situation in Kindergarten C was markedly different. The five specialists agreed that the teacher in this school lacked any enthusiasm for teaching. Specialist C, a physical education expert, was particularly interested whether the teachers actively participated in and interacted with the children during physical activities. She noted that the Kindergarten $\mathrm{C}$ teacher most definitely did not. She also criticised this teacher for her harsh tone with children during conflicts. In sum, the Kindergarten $C$ teacher was assessed as never smiling at the children, repeatedly using the same teaching methods, seldom allowing the children to participate freely and actively and rarely responding positively to their performance.

\section{Discussion}

The objectives of this study were to identify the learning and teaching approaches used in kindergartens that the EDB rated as having different levels of quality, and to compare these ratings with those of specialists (pre-primary teacher educators). Analysis of the specialist focus group discussion revealed two main findings about the learning and teaching practices in the three kindergartens and their resultant quality. First, although there was an 18-month interval between the EDB assessments and those of the specialists, their conclusions were similar. Both found the quality of instruction to vary markedly across the three kindergartens. Second, the three kindergartens claimed to adopt different approaches to learning, namely, the Montessori, Project and Unit Approaches, and yet the researcher's observations and specialists' comments suggest that none actually implemented their purported approach faithfully. In the specialists' view, this was because the teachers had only a superficial understanding of the theories underpinning these approaches. The biggest differences between the three kindergartens lay in their teaching strategies, methods and materials, and teachers' attitudes. Regardless of which teaching approach a kindergarten adopts, the most important factor is the teachers' mastery of the concepts and practices of that approach. The findings of this study support the hypothesis that the quality of pre-primary education depends on the process and implementation of the teaching approach adopted. 
THE INTERNATIONAL JOURNAL OF EARLY CHILDHOOD LEARNING

\section{Superficial Adoption of Teaching Approaches}

As noted, the specialists concurred that the superficial application of kindergartens' purported teaching approaches was the result of the teachers' superficial understanding of the theories underlying them. The following analysis compares the three approaches with the actual teaching conditions in the three kindergartens.

\section{Learning and Teaching in Kindergarten A}

The Montessori Approach states that children must be taught in a "well-equipped" environment that affords free access to teaching materials at any time. Teachers should focus on children's intrinsic needs, give them enough time to manipulate the teaching tools, carry out their own "research" and provide individual counselling as needed, and they should not interfere with the children's spontaneous interest and level of participation (Montessori 1967).

In contrast to these stipulations, however, Kindergarten A had implemented group and section learning, rather than individual learning. Further, its teachers had received no professional training in the Montessori Approach other than guidance from the principal, and the teaching tools and environment did not accord with Montessori practice. Although Kindergarten A focused on children's participation and teacher-child interaction, and the teachers were observed to encourage the children to use their imagination in a concrete and visible way, it did not allow them to select "learning corners" freely and the corners that were available were not decorated with thematic content, as specified in the Montessori Approach. Also, although the teacher arranged a variety of teaching materials and activities, they were relatively monotonous and the children were not allowed to select the latter freely. Kindergarten A was clearly unaware - or chose to ignore - that the key to the effectiveness of the Montessori Approach lies in giving children the opportunity to choose activities freely (Qian 2008).

\section{Learning and Teaching in Kindergarten B}

Kindergarten B had an open atmosphere and teachers were encouraged to try different teaching methods. The teacher allowed the children to learn through exploration and interaction with her and the other children. She also provided stimulating materials that were concrete, real and relevant to the children's lives, and gave the children opportunities to choose from among these materials and explore knowledge through active involvement, all of which are characteristics of high-quality pre-primary education (Burchinal, Cryer and Clifford 2002). However, although this kindergarten claimed to use the Project Approach, which emphasises children's authentic experiences and interests (Katz and Chard 2000), the specialists felt that the teacher had only a superficial grasp of its underlying theory.

For example, although interview activities are one of the strategies used in the Project Approach, the teacher failed to implement such activities properly, possibly due to her lack of theoretical understanding. In contravention of the Project Approach, for instance, the teacher chose the interview topics, failed to engage the children in discussion before the interview activities and her objective was to find specific answers. The specialists stressed that the teacher's decision to have the children interview the kindergarten's principal did not take the children's interests into account, although they did at least learn about the concept of interviewing. They suggested that the activity would have been more effective if the teacher had discussed the topic with the children beforehand and also engaged them in a variety of activities, such as going to the library, reading, writing, data analysis, model making, story and art creation and role plays. Kindergarten B teacher's enthusiasm for leading "project activities”, but failure to progress beyond a superficial understanding of the concepts behind them, is typical of the way in which the Project Approach is currently implemented in many Hong Kong kindergartens (Cheng 2006). 


\section{Learning and Teaching in Kindergarten $C$}

The Unit Approach emphasises interaction among children and activity-appropriate teaching materials, but the Kindergarten $\mathrm{C}$ teacher failed in both respects. This kindergarten as a whole was observed to adopt a teacher-dominant approach in which the children remained passive. Any teacher-child interaction that existed tended to occur as part of whole-group instruction, rather than through one-to-one dialogue, which reaffirms the "general tendency of teachers to dominate conversation in the classroom” (Wells 1987, 45).

In addition, the teacher observed by the specialists displayed an authoritarian manner, had overly high expectations of the children and a very detached relationship with them, all of which are indicators of poor classroom quality (Howes and Ritchie 2002). The specialists felt that she had failed to internalise the Unit Approach and had not devised her teaching plan in a systematic manner. She also failed to carry through the unit concept and consistently used unrealistic materials to introduce theme-related activities. Her focus on a pre-set curriculum that was outside the children's experience and her overuse of textbooks and copying exercises also diverged from the theory underpinning the Unit Approach, and from the general tenets of high-quality preprimary education.

Kindergarten $\mathrm{C}$ appeared to be practicing an early form of the Unit Approach in which the teacher talks and the children listen, the teacher teaches and the children learn, and the teacher does and the children watch, in contrast to its current form, which emphasises children's active participation in the learning process ( $\mathrm{Lu} \mathrm{2003).} \mathrm{Although} \mathrm{some} \mathrm{teachers} \mathrm{in} \mathrm{Hong} \mathrm{Kong}$ kindergartens that still use the Unit Approach try to incorporate multi-dimensional activities that emphasise children's experience, most pre-primary teachers in Hong Kong use methods similar to those observed in Kindergarten C.

As noted, the specialists concurred with the EDB's assessment of significant differences in teaching quality across the three kindergartens. Kindergarten A and B's ratings for activity design and implementation, classroom culture and teachers' performance ranged between 3 and 4 (see Table 1), whereas those for Kindergarten $\mathrm{C}$ remained within the 1 to 2 range. It is clear that the classrooms of Kindergartens A and B were of high quality, and those of C low.

\section{Characteristics of High-quality Classrooms}

Peisner-Feinberg et al. (2001) demonstrated that high-quality kindergartens usually provide "well-planned, child-centred and play-oriented" DAP that encourages children to choose activities based on their personal interests. Such institutions also emphasise parental involvement, two-way interaction and context-matched materials, and take advantage of children's natural curiosity. To a certain extent, Kindergartens A and B had adopted DAP, coordinated their programmes with children's learning and implemented those programmes appropriately, as the ratings in Table 1 show.

The National Research Council (2001) recommends that teachers establish close relationships with children by encouraging their active participation in class, engaging them in in-depth conversations and material-aided activities, and checking whether they need assistance. The conversations, language used, games played and positive classroom management strategies adopted by the teachers in Kindergartens A and B showed their effectiveness in this regard. Effective teaching was also evidenced by the range of creative activities, including dramatic play, block building, water and artistic games and language activities such as reading, storytelling and singing.

\section{Characteristics of Low-quality Classrooms}

Research has shown that the characteristics of low-quality classrooms include an emphasis on pre-set programs, a lack of choice for children, the frequent use of direct teaching and large- 


\section{THE INTERNATIONAL JOURNAL OF EARLY CHILDHOOD LEARNING}

group activities. Such developmentally inappropriate practices are reported to be related to poorer reasoning and problem-solving skills (Sigel 1987), poorer academic results (Burts et al. 1990) and less engagement in pro-social behaviour (Burts et al. 1993).

Both the EDB inspectors and specialists criticised Kindergarten C for its emphasis on copying exercises and rote learning. Many pre-primary educators warn against such methods, which are considered to neglect children's social and emotional development. The academic skills approach, which adopts a didactic and teacher-directed "drill and practice" mode, has also been shown to reduce children's confidence and learning enthusiasm (NAEYC 2005; Katz and Chard 2000). It is evident from both the focus group discussion and literature review that teachers' and children's responses, teaching approaches and materials, DAP, structural and process quality and learning outcomes are all important factors in kindergarten quality.

\section{Limitations}

This study has two limitations. First, it is limited by the small sample size of only three participating pre-primary institutions. The sample was small because the principals, teachers and children from the three kindergartens were purposively selected to address the research questions. The three kindergartens offer classes for children aged three to six. However, the learning and teaching activities and the teachers' performances could only be observed in one of the classes for four- to five-year-olds at each kindergarten; thus, the information obtained was limited. It can be used for a basic understanding of the teaching approaches used but it is suggested that longitudinal data be used for a deeper understanding and more in-depth analysis of the teaching approaches and to enhance the validity of the study.

The second limitation is that the teachers and the children may have been aware of the observations taking place in the classroom, and this may have affected some of their responses.

\section{Conclusion}

Learning and teaching are complicated phenomena. This study depicts classroom activities in three kindergartens, and, despite its limitations, shows the different teaching approaches adopted by these kindergartens. In observing the different teaching approaches, this study uncovers best practice in promoting children's learning and demonstrates the importance of assisting teachers to be introspective regarding their own teaching practices and theory. It highlights that teachers must put their own learning into practice. If there is a contradiction between a teacher's practices and theory, then the learning outcomes for the children will not be consistent and the teacher's effectiveness will be lessened, which will lead to a failure to achieve high-quality education (Kim 2003). Conversely, the outcome can be very positive if teachers believe in their own philosophical ideas and master them to produce more learning in children and more developmentally appropriate practice.

If the three participating kindergartens had followed the teaching approaches that they purported to have adopted in a comprehensive fashion, and put the theories underlying those approaches into practice, then they would have achieved higher educational standards. Although the teaching quality of Kindergartens A and B was already relatively high, their implementation of their respective teaching approaches was largely superficial. The findings of this study highlight the danger of the superficial adoption of teaching approaches, and suggest that caution be exercised in adopting new approaches. Rather than simply state that they are implementing a given approach, pre-primary educators should carry out in-depth studies into its implementation to ensure that they are delivering high-quality education. The divergence between theory and practice is the main reason for the simultaneous occurrence of high- and low-quality classrooms in this research. It is hoped that the discussion and analysis presented herein will provide insights into how pre-primary educators can be encouraged to examine their own teaching practices to ensure that they have mastered the fundamental concepts of the approaches they espouse. 
Although the EDB gave different quality ratings to Kindergartens A (good) and B (acceptable), the specialists did not make such a marked distinction. There are several possible explanations. First, there was an 18-month gap between the two ratings and Kindergarten B may have improved in the interim. Second, the 5-point rating scale used in the questionnaire may not have been sufficiently sensitive to tap the distinctions between "good" and "acceptable" kindergartens. Third, the different approaches adopted by the three kindergartens may have engendered different degrees of child-centred pedagogy, although the specialists felt that none of them had implemented their chosen approach with any fidelity.

The results of this study have two major implications for practicing teachers and the Hong Kong government. First, teachers must understand that the teaching approach they adopt is strongly related to the quality of the education they provide. Second, the government needs to expand professional training for pre-primary teachers to improve pre-primary educational quality. Regardless of the teaching approach adopted, teachers must fully grasp its underlying theory to carry it out effectively. Several teaching strategies are recommended for the delivery of truly high-quality pre-primary education. To improve active learning, teachers need to cultivate patience and allow children sufficient time to learn, which involves adjustment to children's rate of cognition. Teachers should also explore children's interests and concerns and draw upon their strong and natural sense of curiosity, and then take both as their point of departure in teaching. Copple and Bredekamp (2006) argued that the best way to promote children's construction of knowledge is to engage their interest.

Specialist D, who is the author of the textbook used by the participating kindergartens, recommended that schools provide varied learning content and an environment to match the teaching materials they select, which is not only an important prerequisite for active learning, but also a basic requirement for effective teaching. In a varied and flexible learning environment, children can choose materials on their own and decide what to do with them, thereby enabling them to adjust their existing experiences actively, clarify any misunderstandings and solve problems themselves. When their participation is required, teachers should try their best to provide a choice of content and materials of varying levels of difficulty.

This study illustrates some of the typical learning and teaching approaches and methods employed in Hong Kong kindergartens, and sheds light on the measures that need to be taken in the provision of high-quality pre-primary education in different countries. It is hoped that researchers will carry out more in-depth studies into other areas related to the delivery of highquality pre-primary education, such as the provision of teacher training subsidies, teachers' beliefs and practices, and methods for relieving parental worries over the pre-primary to primary transition. In-depth case studies of the learning and teaching methods of the Project, Montessori and Unit Approaches would also be of value, particularly in light of the recent pedagogical changes in the latter approach. 


\section{REFERENCES}

Andersson, Bengt-Erik. 1989. "Effects of Public Day-care: A Longitudinal Study.” Child Development 60: 857-866.

Belsky, J., Deborah Lowe Vandell, Margaret Burchinal, K. Alison Clarke-Stewart, Kathleen McCartney, and Margaret Tresch Owen. 2007. "Are There Long-term Effects of Early Child Care?” Child Development 78(2): 681-701.

Bredekamp, Sue. 1987. Developmentally Appropriate Practice in Early Childhood Education Programs. Serving Children from Birth through Age 8. Washington, DC: National Association for the Education of Young Children.

Burchinal, Margaret R., Debby Cryer, and Richard M. Clifford. 2002. "Caregiver Training and Classroom Quality in Child Care Centres.” Applied Development Science 6(1): 2-11.

Burchinal, Margaret R., Joanne E. Roberts, Rhodus Riggins Jr., Susan A. Zeisel, Eloise Neebe, and Donna Bryant. 2000. "Relating Quality of Center-based Child Care to Early Cognitive and Language Development Longitudinally.” Child Development 71: 339357.

Burts, Diane C., Craig H. Hart, Rosalind Charlesworth, D. Michele Dewolf, Jeanette Ray, and Karen Manuel. 1993. "Developmental Appropriateness of Kindergarten Programs and Academic Outcomes in First Grade.” Journal of Research in Childhood Education 8(1): 23-31.

Ceglowski, Dedorah, and Chiara D. Bacigalupa. 2002. "Four Perspectives on Child Care Quality.” Early Childhood Education Journal 30: 87-92.

Cheng, Pui Wah Doris. 2006. "The Translation of Western Teaching Approaches in the Hong Kong Early Childhood Curriculum: A Promise for Effective Teaching?” Contemporary Issues in Early Childhood 7(3): 228-237.

Chien, Chu-ying. 2002. Theoretical orientations and practical experience of approaches in early childhood education. Taipei: Psychological Publishing Co. Ltd. (In Chinese)

Clarke-Stewart, Kathleen Alison, and Virginia Allhusen. 2002. "Nonparental Caregiving." In Handbook of Parenting, second edition, edited by M.H. Bornstein, 215-252. Mahwah, NJ: Erlbaum.

Clifford, Richard, and Donna Bryant, Multi-state Study of Pre-kindergarten. 2002. Chapel Hill, NC: National Centre for Early Development \& Learning, University of North Carolina.

Copple, Carol, and Sue Bredekamp. 2006. Basics of Developmentally Appropriate Practice: An Introduction for Teachers of Children 3-6. Washington, DC: National Association for the Education of Young Children.

Galinsky, Ellen, Carollee Howes, Susan Kontos, and Marybeth Shinn. 1994. The Study of Children in Family Child Care and Relative Care: Highlights of Findings. New York: Families and Work Institute.

Hong Kong Christian Service. 1994. Development Curriculum and Activity Suggestions for Early Children at the Ages of Two to Four. Hong Kong: Hong Kong Christian Service. (In Chinese)

Hong Kong Government. 2000. Policy Address. Hong Kong: Government Printer.

Howes, Carollee, and Sharon Ritchie. 2002. A Matter of Trust: Connecting Teachers and Learners in the Early Childhood Classroom. New York: Teachers College Press.

Huo, Liyan, \& Qi, Xiaotian. 2008. "Key Solutions and Basic Threads on Taking Montessori Method for Reference in Chinese Kindergartens.” Educational Sciences 2: 1-4. (In Chinese)

Kamii, Constance, and Janice K. Ewing. 1996. "Basing Teaching on Piaget's Constructivism.” Childhood Education 75(5): 260-268.

Katz, Lilian G., and Sylvia C. Chard. 2000. Engaging Children’s Minds: The Project Approach, second edition. Stanford, CT: Ablex. 
Kim, Seock Ho. 2003. "The Relationships Between Kindergarten Teachers' Beliefs and Practices about Developmentally Appropriate Practice (DAP): The Effects of Self-efficacy.” The Journal of Korean Teacher Education 20: 85-104.

Liu, Yü Yan. 2003. "From tradition to Openness: Development of Chia Mei Thematic Approach.” In Curriculum Approaches from Early Childhood Education, edited by Chien Ch`u-ying, 122. Taipei: Psychological Publishing. (In Chinese)

Lu, Su-pi. 2003. "Unit Approach.” In Curriculum Approaches from Early Childhood Education, edited by Ch’u-ying Chien, 7-53. Taipei: Psychological Publishing. (In Chinese)

McCartney, Kathleen. 1984. "Effect of Quality of Day Care Environment on Children's Language Development.” Developmental Psychology 20(2): 244-260.

Montessori, Maria. 1964. The Montessori Method. New York: Schocken Books.

Montessori, Maria. 1967. The Discovery of the Child. Notre Dame, IN: Fides.

Morrison, Henry Clinton. 1931. The Practice of Teaching in the Secondary School. Chicago: University of Chicago Press.

Moss, Peter, Gunilla Dahlberg, and Alan Pence. 2000. "Getting Beyond the Problem with Quality.” European Early Childhood Education Research Journal 8(2): 103-115.

National Association for the Education of Young Children. 2005. Teachers: A Guide to the NAEYC Early Childhood Program Standard and Related Accreditation Criteria. Washington, DC: National Association for the Education of Young Children.

National Institute of Child Health and Human Development. 2002. "Child-care StructureProcess-Outcome: Direct and Indirect Effects of Child-care Quality on Young Children’s Development.” Psychological Science 13(2): 199-206.

National Association for the Education of Young Children. 2006. New NAEYC: Early Childhood Program Standards and Accreditation Criteria. Washington, DC: National Association for the Education of Young Children.

National Research Council. 2001. "Eager to Learn: Educating our Preschoolers.” In Commission on Behavioral and Social Sciences and Education, edited by Committee on Early Childhood Pedagogy, B.T. Bowman, M.S. Donovan, and M.S. Burns, 128-181. Washington, DC: National Academy Press.

Peisner-Feinberg, Ellen S., Margaret R. Burchinal, Richard Clifford, Mary L. Culkin, Carollee Howes, and Sharon Lynn Kagan. 2001. "The Relation of Pre-school Child-care Quality to Children’s Cognitive and Social Developmental Trajectories through Second Grade.” Child Development 72: 1534-1553.

Pianta, Robert C., Karen M. La Paro, Chris Payne, Martha J. Cox, and Robert Bradley. 2002. "The Relation of Kindergarten Classroom Environment to Teacher, Family and School Characteristics and Child Outcomes.” Elementary School Journal 102(3): 225-238.

Qian, Wen. 2008. "On Montessori Educational Method: Advantages and Limitations." Educational Sciences 2: 5-8. (In Chinese)

Sheridan, Sonja. 2001. Pedagogical Quality in Preschool: An Issue of Perspectives. Gothenburg: Acta Universitatis Gothoburgensis.

Sigel, Irving E. 1987. "Does Hothousing Rob Children of Their Childhood?” Early Childhood Research Quarterly 2: 211-225.

Siraj-Blatchford, Iram, Kathy Sylva, Stella Muttock, Rose Gilden, and Danny Bell. 2002. Researching Effective Pedagogy in the Early Years. Oxford: Department of Educational Studies, University of Oxford.

Stipek, Deborah J. 1993. "Is Child-centered Early Childhood Education Really Better?” In Advances in Early Education and Day Care: Perspectives on Developmentally Appropriate Practice, edited by S. Reifel, 29-52. Greenwich, CT: JAI Press.

Sun, Pang-cheng. 1969. Basic Concepts of the Unit Approach. Taipei: Psychological Publishing Co. Ltd. (In Chinese) 
Sylva, Kathy. 1994. "School Influences on Children's Development." Child Psychology and Psychiatry 35: 135-170.

Sylva, Kathy, Edward Melhuish, Pam Sammons, Iram Siraj-Blatchford, and Brenda Taggart. 2004. The Effective Provision of Pre-school Education (EPPE) Project: Findings from Preschool to the End of Key Stage. London: Institute of Education, University of London.

The Organisation for Economic Co-operation and Development. 2012. Starting strong III: A quality toolbox for early childhood education and care. Paris: OECD.

U.S. Department of Education. 2000. Building Strong Foundations for Early Learning: The U.S. Department of Education's Guide to High-quality Early Childhood Education Programs. Washington, DC: U.S. Department of Education.

Wang, Ching-chu. 1987. Kindergarten Education. Taichung: Taichung Normal College. (In Chinese)

Wells, Gordon. 1987. The Meaning Makers, Children Learning Language and Using Language to Learn. London: Hodder and Stoughton.

Wong, Ngai Chun, Loraine Corrie, Hui Li, Yuen Ling Li, Swee Eng Lim, and Wai Yum Wong. 2003. Guide to Using the Pre-primary Performance Indicators in Learning and Teaching. Hong Kong: Hong Kong Institute of Education.

Wong, Ngai Chun, Yin Man Yung, and Sing Pui Chan. 2007. Practice Guidelines on Curriculum-based Child Assessment Model for Quality Early Childhood Programme. Hong Kong: Hong Kong Institute of Education. (In Chinese) 


\section{Appendix 1}

\section{Classroom Observation Form}

\section{Rating}

In this part of the form, members of the focus group rated each of the key indicators in different categories on a scale from 1 (not at all) to 5 (to a great extent). The number 6, or "N/A", was used when the specialists considered the indicator inappropriate given the purpose and context of the activities, or when there was insufficient evidence to make a judgment.

\section{Design of Activities}

\section{Ratings for Key Indicators}

\begin{tabular}{|c|c|c|c|c|c|c|}
\hline & $\begin{array}{l}\text { Not } \\
\text { at }\end{array}$ & & & & $\begin{array}{l}\text { To a } \\
\text { great }\end{array}$ & \\
\hline & $\underline{\text { all }}$ & & & & extent & N/A \\
\hline $\begin{array}{l}\text { The design of the activities reflected } \\
\text { careful planning and organisation. }\end{array}$ & 1 & 2 & 3 & 4 & 5 & 6 \\
\hline $\begin{array}{l}\text { The teaching methods matched the } \\
\text { children's developmental progress. }\end{array}$ & 1 & 2 & 3 & 4 & 5 & 6 \\
\hline $\begin{array}{l}\text { The teaching programme included all } \\
\text { development domains. }\end{array}$ & 1 & 2 & 3 & 4 & 5 & 6 \\
\hline $\begin{array}{l}\text { The teaching plan included provision for } \\
\text { individual differences. }\end{array}$ & 1 & 2 & 3 & 4 & 5 & 6 \\
\hline $\begin{array}{l}\text { The variety of learning experiences } \\
\text { allowed the children choice. }\end{array}$ & 1 & 2 & 3 & 4 & 5 & 6 \\
\hline $\begin{array}{l}\text { The learning experiences involved } \\
\text { problem-solving activities. }\end{array}$ & 1 & 2 & 3 & 4 & 5 & 6 \\
\hline $\begin{array}{l}\text { Creative learning experiences were } \\
\text { anned. }\end{array}$ & 1 & 2 & 3 & 4 & 5 & 6 \\
\hline
\end{tabular}


THE INTERNATIONAL JOURNAL OF EARLY CHILDHOOD LEARNING

\section{Implementation of Activities}

Ratings for Key Indicators

8. Age-appropriate learning experiences matched learning objectives.

9. Experiences that fostered the children's learning were provided.

10. The activities were systematically adjusted to accommodate children's needs and interests.

11. A safe environment with adequate facilities that facilitated learning was provided (e.g., mobility, use of equipment).

12. The environment stimulated learning and facilitated problem solving and exploration.

13. The activities supported children's choice and collaborative learning.

14. The activities built on children's abilities and interests.

15. The activities were adapted to individual differences.

16. The activities promoted children's selfcare skills, self-confidence and sense of security.

$\begin{array}{lllll}1 & 2 & 3 & 4 & 5\end{array}$




\section{Classroom Culture}

\section{Ratings for Key Indicators}

17. The active participation of all was encouraged.

18. There was a climate of respect for children's ideas, questions and contributions.

19. The interactions reflected collaborative working relationships between teacher and children.

$\begin{array}{lllll}1 & 2 & 3 & 4\end{array}$

20. Questions were raised to enhance and extend children's learning (e.g., provocative and open questions).

1

1

21. Communication with children enhanced mutual respect and relationships.

22. Different strategies were used to communicate with individual children.

\section{Teachers' Performance}

\section{Ratings for Key Indicators}

23. The teacher made eye contact with the children during lessons.

24. The teacher allowed the children to have thinking time. 
THE INTERNATIONAL JOURNAL OF EARLY CHILDHOOD LEARNING

25. The teacher asked a large number of questions.

26. The teacher attributed children's successes to their efforts.

27. The teacher conveyed a sense of enthusiasm in the presentation of tasks.

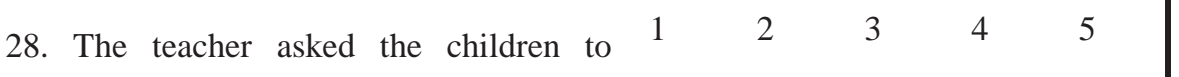
restate answers.

29. The teacher gave clear and detailed instructions and explanations.

30. The teacher gave a moderate amount of praise.

31. The teacher made brief contact with individual children.

32. The teacher encouraged the children to ask questions and initiate verbal interaction.

\begin{tabular}{|c|c|c|c|c|}
\hline 1 & 2 & 3 & 4 & 5 \\
\hline 1 & 2 & 3 & 4 & 5 \\
\hline 1 & 2 & 3 & 4 & 5 \\
\hline 1 & 2 & 3 & 4 & 5 \\
\hline 1 & 2 & 3 & 4 & 5 \\
\hline 1 & 2 & 3 & 4 & 5 \\
\hline 1 & 2 & 3 & 4 & 5 \\
\hline 1 & 2 & 3 & 4 & 5 \\
\hline
\end{tabular}

Adapted from:

Weiss, Iris R., Joan D. Pasley, P. Sean Smith, Eric R. Banilower, and Daniel J. Heck. 2003. A Study of K-12 Mathematics and Science Education in the United States. Inside the Classroom: Observation and Analytic Protocol (pp. 1-6). Chapel Hill, NC: Horizon Research.

Source:

Wong, Ngai Chun, Loraine Corrie, Hui Li, Yuen Ling Li, Swee Eng Lim, and Wai Yum Wong. 2003. Guide to Using the Pre-primary Performance Indicators in Learning and Teaching. Hong Kong: Hong Kong Institute of Education. 


\section{Appendix 2}

\section{Questions for Focus Group Discussion}

1. What are your views on the learning and teaching approaches adopted by the three kindergartens?

2. What are your views on the teaching performance of the teachers from the three kindergartens? (Teaching performance includes the setting up of the learning environment, preparation of learning and teaching materials, arrangement of learning activities and stimulation of teacher-child and child-child interactions.)

3. What does high-quality pre-primary education mean to you in terms of learning and teaching?

4. What are the factors affecting teachers' choices of learning and teaching approaches?

\section{ABOUT THE AUTHORS}

Wai Ling Chan, The Hong Kong Institute of Education, China

Nirmala Rao, The University of Hong Kong, China 